\title{
CASE OF PRIMARY TUBERCULOSIS OF THE CERVIX UTERI, FOR WHICH VAGINAL HYSTERECTOMY WAS PERFORMED.
}

By W. H. B. BROOK, M.D., F.R.C.S., Surgcon to the Lincoln County Hospital.

(Read at the Obstetrical Society of London, May 6th, 1903.)

Mrs. A., aged 50, was seen on February 20th, 1903, complaining of leucorrhœa, pain in the sacral region, and loss of flesh for the past two months. She had had one child at the age of 21, and four miscarriages, the last 12 years ago, after which a pessary was worn for about a year. Five years ago the uterus had been curetted for endocervicitis. Since that time she has suffered several times from cervical catarrh, but she always came at once for examination and treatment, having a great fear of cancer, from which some friend of hers had died. A mixture containing iron, bromide of potassium and nux vomica always had a good effect. The last time that she had been previously seen was on March 21st, 1902, when a note was made that " nothing abnormal was discovered." The catamenia had been irregular for the last three years, being last seen at the end of December, 1902. They had never been excessive, nor had there ever been any loss except at the period.

Previous history. Influenza 12 years and pneumonia 9 years ago. Her own statement is that she has been ailing all her life, but with respect to this her neurotic temperament must be taken into consideration.

Family history. Mother died of phthisis aged 40, as also did brother aged 36 . The patient's husband, a farmer, is a strong, healthy man.

Condition on February 20th, 1903. She was a sparely-built, active woman, of a decidedly neurotic temperament, hair very grey, complexion sallow, suffers from constipation. The lungs, heart and kidneys appeared to be healthy. Nothing abnormal was detected on examination of the abdomen.

On vaginal examination there was a certain amount of leucorrhoa. There was a circular ulcer the size of a sixpence on the anterior lip of the cervix extending into the external os. Its edge was sharply defined, the surrounding tissue appearing slightly raised, the surface was rather granular, ragged and pitted, and somewhat pale in colour. 
There was no induration of the cervix, which did not bleed on examination more readily than usual, nor was the surface of the ulcer friable. The uterus was not enlarged, and was freely movable; no enlarged glands could be detected.

Although the appearance of the cervix was not typical of carcinoma, yet it was so unlike a simple eversion, resembling rather a patch of lupus vulgaris, that a small piece was sent for examination to the Clinical Research Association, who reported that although the portion sent was too small for a thoroughly satisfactory examination, yet, so far as could be ascertained the lesion was of a tubercular nature.

On March 12th, under chloroform, the whole of the affected area was excised, iodised phenol being applied to the endometrium and cervix. As no evidence of tubercle could be found elsewhere this must have been a primary lesion.

On March 26 th the cervix presented the same appearance of an indolent ulcer with sharply cut edges, and a depressed ragged surface, but now the posterior lip was affected as much as the anterior. It was therefore decided to extirpate the uterus, but on the day fixed for the operation the catamenia reappeared, the flow being perfectly natural in character.

On A pril 4th, the uterus was removed by vaginal hysterectomy, the broad ligaments being secured by pressure forceps. As the ovaries appeared healthy they were not removed. There was remarkably little hæmorrhage from the cut vaginal mucous membrane, due $I$ think to the administration of chloride of calcium for some days beforehand. The vagina was lightly packed with iodoform gauze which was changed the next day. The pressure forceps were removed at the end of 48 hours.

The patient made an uneventful recovery, and has now put on flesh and looks in better health than she has done for some months.

Remarks. This case is of some interest as an instance of primary tuberculosis of the cervix, viz., tuberculosis of the cervix occurring in a patient who shows no signs of any tubercle elsewhere, not even the vagina being affected.

In the Transactions of the Obstetrical Society for 1902, a case is reported by Dr. Lewers, who refers to two other instances, and in the same volume are the notes of two cases recorded by Dr. Horrocks and Dr. Croft. As to the treatment which was adopted, Professor Pozzi in his Treatise on Gynacology, vol. iii., p. 142, says that: "There should be no hesitation in performing hysterectomy even for a very circumscribed ulceration of the cervix if the diagnosis be certain;" 


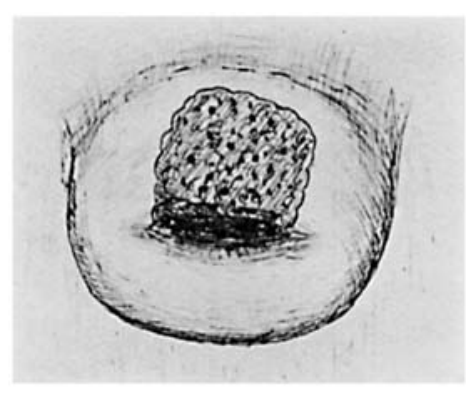

FIG. I.

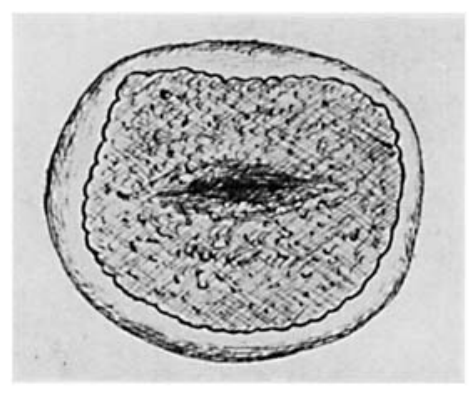

FIG. II.

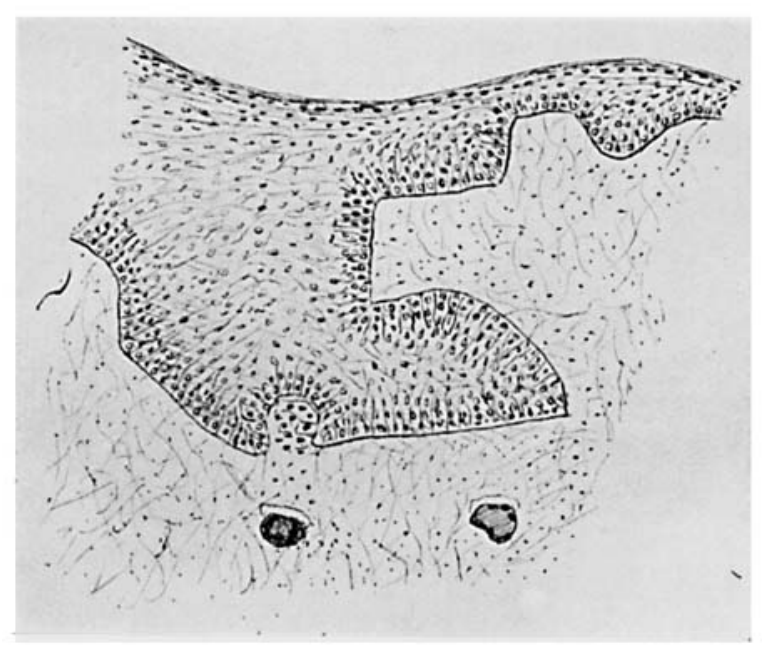

Fra. III. 


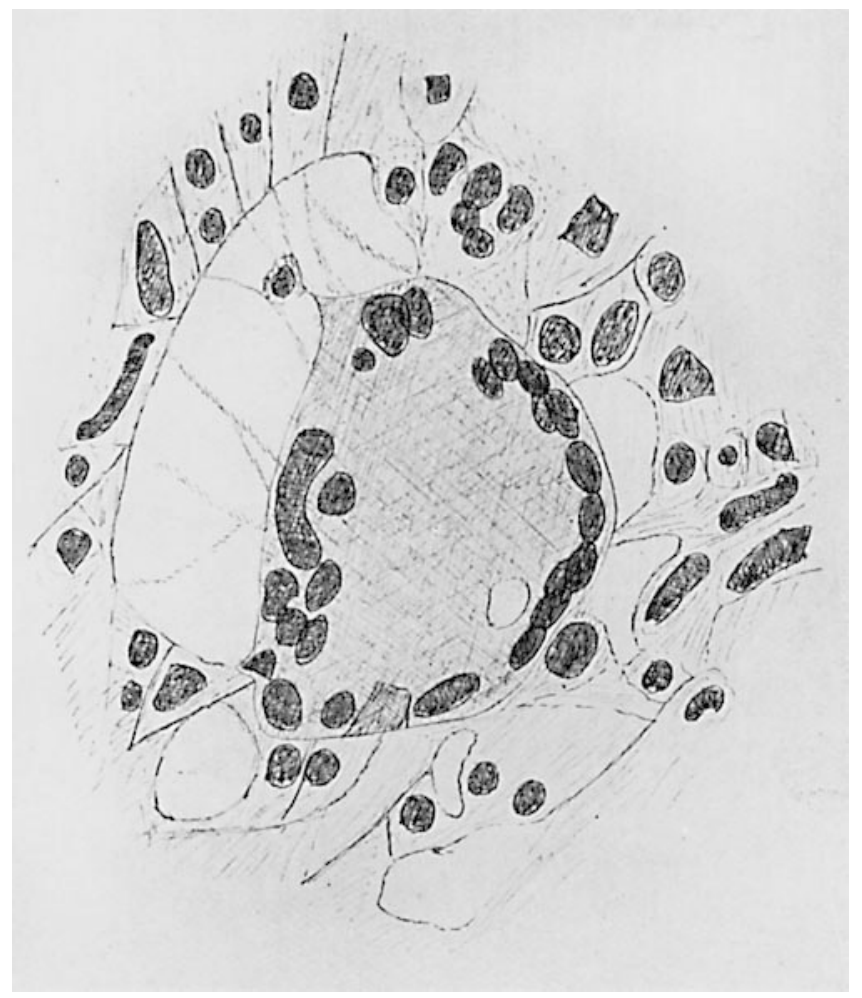

Fig. IV. 


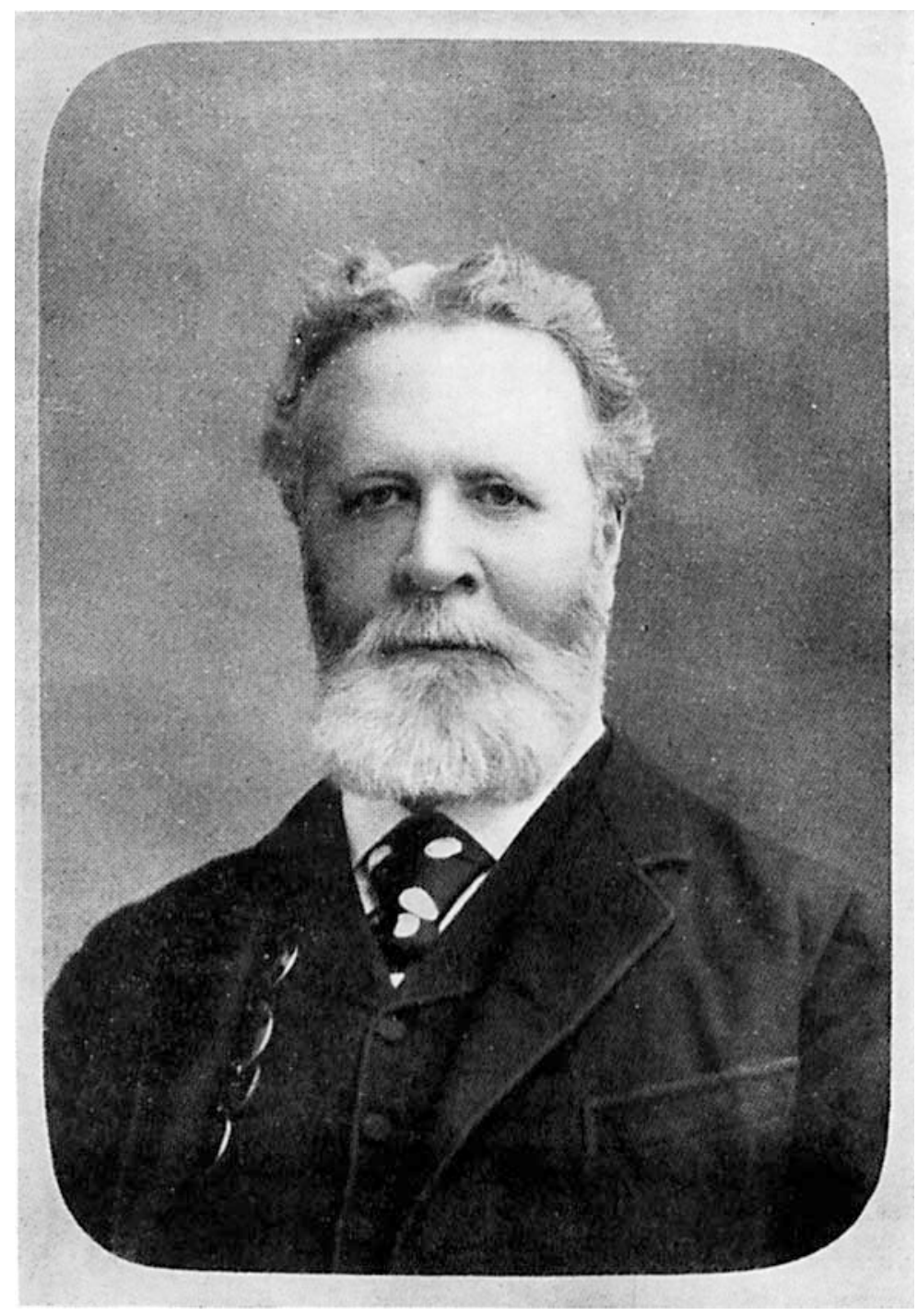

T. Gaillard Thomas, M.D., LL.B. 
and Dr. Lewers (op. cit.) says: "that given a case of primary tuberculosis of the cervix, where there is reason to believe there is no tubercle elsewhere, vaginal hysterectomy is the right treatment." Considering, however, the similarity between the lesion in these cases and that of lupus, and the value of the application of the Röntgen rays in the latter disease, it is a question whether we ought not to adopt that method of treatment, care being taken, however, not to lose valuable time in so doing.

On examination the disease was found to be limited to the cervix, extending half an inch up the canal, the body of the uterus being healthy. Typical multi-nucleated giant cells were seen in the submucosa of the cervix.

\section{Description of Drawings.}

I. Condition of the cervix when first seen on February 20th, showing a depressed ulcer the size of a sixpence on the anterior lip, extending into the os externum. The margin of the ulcer is sharply cut, the surrounding tissues being slightly raised.

II. Condition of cervix (after removal of the uterus on April 4th). The ulcer has now extended over the posterior as well as the anterior lip.

III. Section of cervix showing columnar epithelium, and two giant cells in the submucosa. $\times 160$.

IV. Portion of the same section $\times 844$, showing a multinucleated giant cell surrounded by epithelioid cells.

V. A similar giant cell. $\times 800$. 